Egyptian Journal of Aquatic Biology \& Fisheries

Zoology Department, Faculty of Science,

Ain Shams University, Cairo, Egypt.

ISSN $1110-6131$

Vol. 26(1): 23 - 43 (2022)

www.ejabf.journals.ekb.eg

\title{
Applications of chitosan and chitosan nanoparticles in fish aquaculture
}

Marwa El-Naggar *, Fareda Medhat and Ayat Taha

Department of Zoology, Faculty of Science, Ain Shams University, Abbassia, Cairo 11566, Egypt.

*Corresponding Author: m.alnggar@ hotmail.com

\section{ARTICLE INFO}

Article History:

Received: Dec. 25, 2021

Accepted: Jan.3, 2022

Online: Jan. 10, 2022

\section{Keywords:}

Aquaculture,

Feed additive,

Chitosan,

Chitosan nanoparticle,

Drug delivery,

Immunostimulant

\begin{abstract}
Aquaculture aims to provide stable environmental conditions for fish to be able to grow and protect it from stress and diseases. In order to guarantee a sustainable yield of fish species, well-balanced diets should be considered. For this purpose, diets supplemented with feed additives have won the interest of researchers who are concerned with the aquaculture field, the most important of which are chitosan and chitosan nanoparticles. Chitosan [ $\beta-(1-4)-\mathrm{N}$-acetyl-D-glucosamine] is a cationic biopolymer, derived from the alkaline deacetylation of chitin; a natural polymer found in the exoskeletons of insects, crustaceans and fungal cell walls. Chitosan nanoparticles were synthesized either by chemical or physical cross linking. Chitosan nanoparticles are favored due to their large surface area, bioavailability and deep penetration to the target sites. Chitosan and chitosan nanoparticles have several unique biological properties that enable them to act as promising materials in variable applications, including biosafety, biocompatibility, improved solubility and biodegradability. The afore-mentioned properties enabled them to be used in several applications in fish aquaculture, such as enhancing growth performance and immune functions. Moreover, they act as safe feed additives, drug carriers and are widely used in water treatment as well. The applications of chitosan and chitosan nanoparticles in fish aquaculture attracted the interest of many researchers. The present review covered all information concerning the effect of chitosan and chitosan nanoparticles on fish, including antioxidant activity, growth enhancement and immunostimulatory effects. The discussed studies in the current review proved that chitosan and chitosan nanoparticles are regarded as promising materials with wide applications in fish aquaculture.
\end{abstract}

\section{INTRODUCTION}

Fish aquaculture is considered an important agricultural activity capable of ending nutritional deficiencies and contributing to poverty reduction (Kaleem \& Sabi, 2021). During the past couple of decades, a remarkable and enormous progression in aquaculture has outpaced capture fisheries. While, in the upcoming years, it is predicted to serve as a principal source of aquatic animal requirements (Maclean, 2003 and Ahmed et al., 2020). Thus, fish demand continues to grow throughout the world moving towards intensive aquaculture systems, especially in the developing countries, where fish are important source of the animal protein and the artificial feeding, where fish form the major component (Maclean, 2003 and Abdel-Ghany \& Salem, 2020). Recently, aquaculture has been 
estimated to provide about $75 \%$ of the total fish production in Egypt on an annual basis (GAFRD, 2020).

In order to guarantee continuous growth in aquaculture, it is necessary to develop new unconventional fish diets that can promote physiological and biological functions of the cultured fish. Consequently, scientists must search for green, ecofriendly, renewable, valuable and biologically sustainable material to attain aquaculture development (AbdelGhany \& Salem, 2020). Chitosan (CS) and chitosan nanoparticles (CSNP) are considered as safe, natural cationic biopolymers, which enhance fish growth and promote its immune response (El-Naggar, 2020).

CS is obtained from the deacetylation of chitin, an important component found in the exoskeletons of aquatic crustaceans, such as shrimps, crabs and crayfish and terrestrial organisms as well as the cell walls of some microorganisms (Xu et al., 2008).

On the other hand, nanotechnology is one of the speediest developing fields that provide novel nano-enabled products with innovative and unique uses. Nanoparticles are the key elements for the success of the nanotechnology industry, with a size ranging from 1 to $100 \mathrm{~nm}$ on at least one dimension. The nanoparticles have distinctive physico-chemical characteristics that are different from their bulk materials. They are distinguished for their larger surface area to volume ratio, which results in a higher reactivity and significant properties (Khosravi-Katuli et al., 2017).

CS and CSNP can be applied in different fields, such as water treatment, agriculture and cancer treatment. Moreover, in aquaculture they act as natural and non-toxic feed additives, enhancing the fish growth performance, ameliorating immune function and inhibiting intestinal microbial pathogens (El-Naggar, 2020).

The current review clarified profound data with respect to CS and CSNP, regarding their extraction, preparation, surface morphology as well as their applications in fish aquaculture. This data would serve as a guide for all those in concern.

\section{Chitosan: structure and preparation}

CS (Poliglusam) [ $\beta-(1-4)-N$-acetyl-D-glucosamine] is a biocompatible, non-toxic product and biodegradable polymer which is soluble in acidic aqueous solution. CS has distinguishable properties, including non-toxicity, biodegradability, biocompatibility and improved solubility (Shard $\boldsymbol{e t}$ al., 2014) and easy and applicable modification, which suits various fields, such as aquaculture, cosmetics, cancer therapy, drug carrier and water treatment (Ahmed et al., 2019; Abd-Elghany \& Salem, 2020 and El-Naggar et al., 2021).

\subsection{CS chemical structure and sources}

CS chemical structure is $\beta$ - $(1 \rightarrow 4)$-linked D-glucosamine (deacetylated unit) and Nacetyl-D-glucosamine (acetylated unit) (Fig. 1). It is extracted from chitin, the second most abundant polysaccharide after cellulose that is obtained from the exoskeletons of aquatic organisms, including: fish, shrimps, crabs and some insects as well as cell wall of some fungi under specific deacetylation procedures (Fig. 2) (No \& Meyers, 2010; Abdel-Ghany \& 
Salem, 2020 and Perini et al., 2020). Chitin and cellulose have the same chemical structure, except that chitin composition contains nitrogen compared to cellulose which lacks nitrogen (Fig. 3) (Abdel-Ghany \& Salem, 2020).

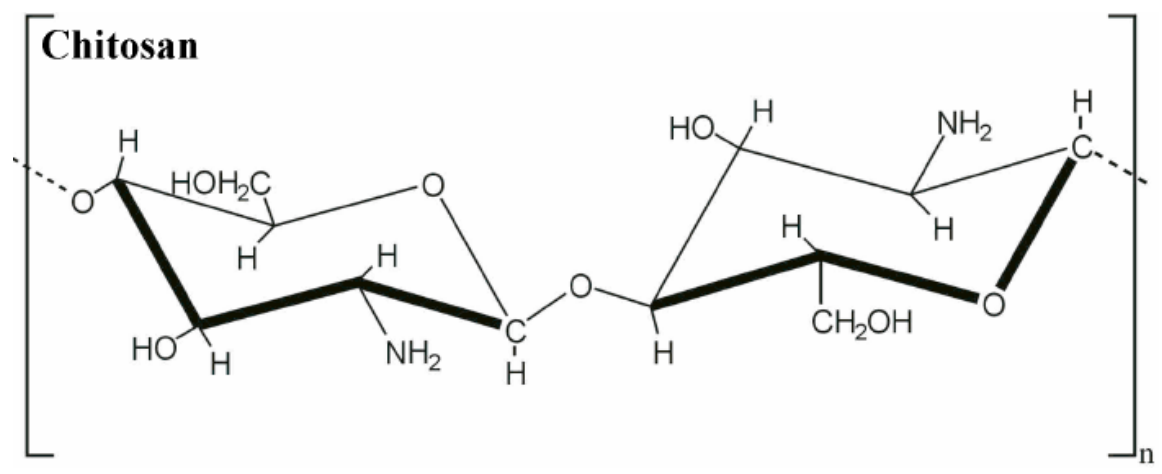

Fig. 1. The chemical structure of Chitosan (López-García et al., 2014)

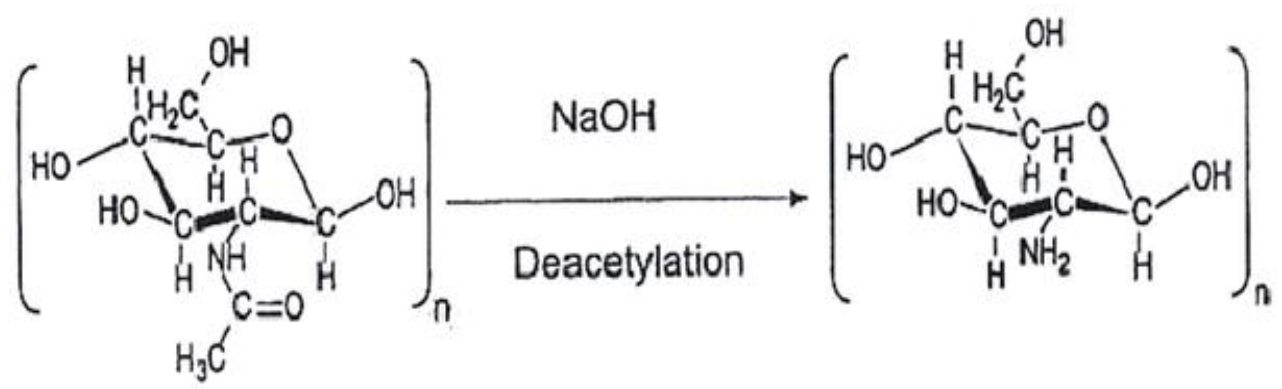

Chitin

Chitosan 2-acetamido-2-deoxy- $\beta$-D-glucose-( $\mathrm{N}$-acetylglucosamine)

Fig. 2. Chitin deacetylation (Saifuddin \& Palanisamy, 2005)

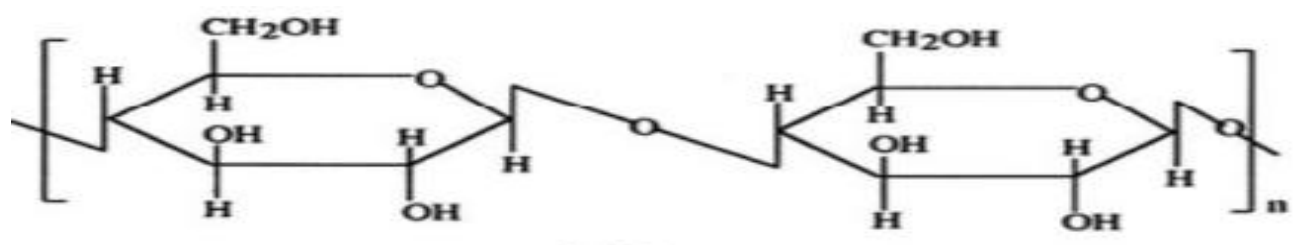

Cellulose

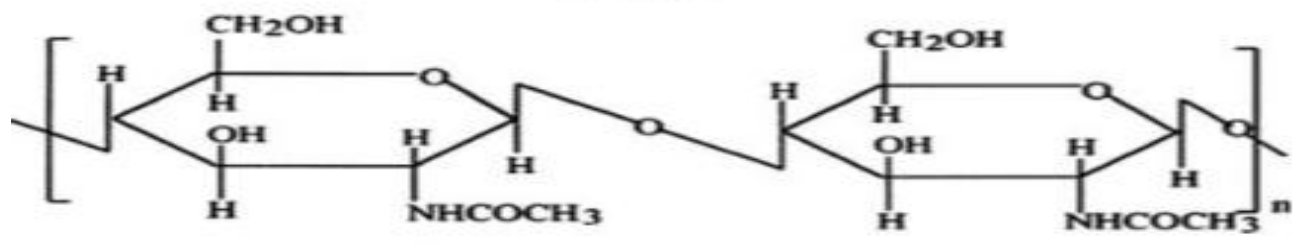

Chitin

Fig. 3. Chitin and cellulose chemical structure (Chawla et al., 2015) 


\subsection{Extraction of chitin from the exoskeleton wastes and its conversion into chitosan}

The exoskeletons of crustaceans contain three main components; namely, proteins (20-40\%), chitin (15-40\%) and $\mathrm{CaCO}_{3}(20-50 \%)$ as well as little amounts of pigment and salts (Kurita, 2006 and Pakizeh et al., 2021). Accordingly, chitin extraction follows 4 main steps: 1. Demineralization in which $\mathrm{CaCO}_{3}$ is eliminated by $\mathrm{HCl} ; 2$. deproteinization for protein removal; it is performed by $\mathrm{NaOH}$; 3. decoloration / bleaching in which pigments and salts are removed, and 4. deacetylation, which is the conversion of chitin into CS by the removal of acetyl groups (Fig. 4) (El-Naggar et al., 2019). The arrangement of the aforementioned steps differs from one author to another, resulting in CS with different physicochemical characteristics. The quality of CS is also affected by the method of chitin extraction, deacetylation method, reaction time and temperature (Pakizeh $\boldsymbol{e t}$ al., 2021).

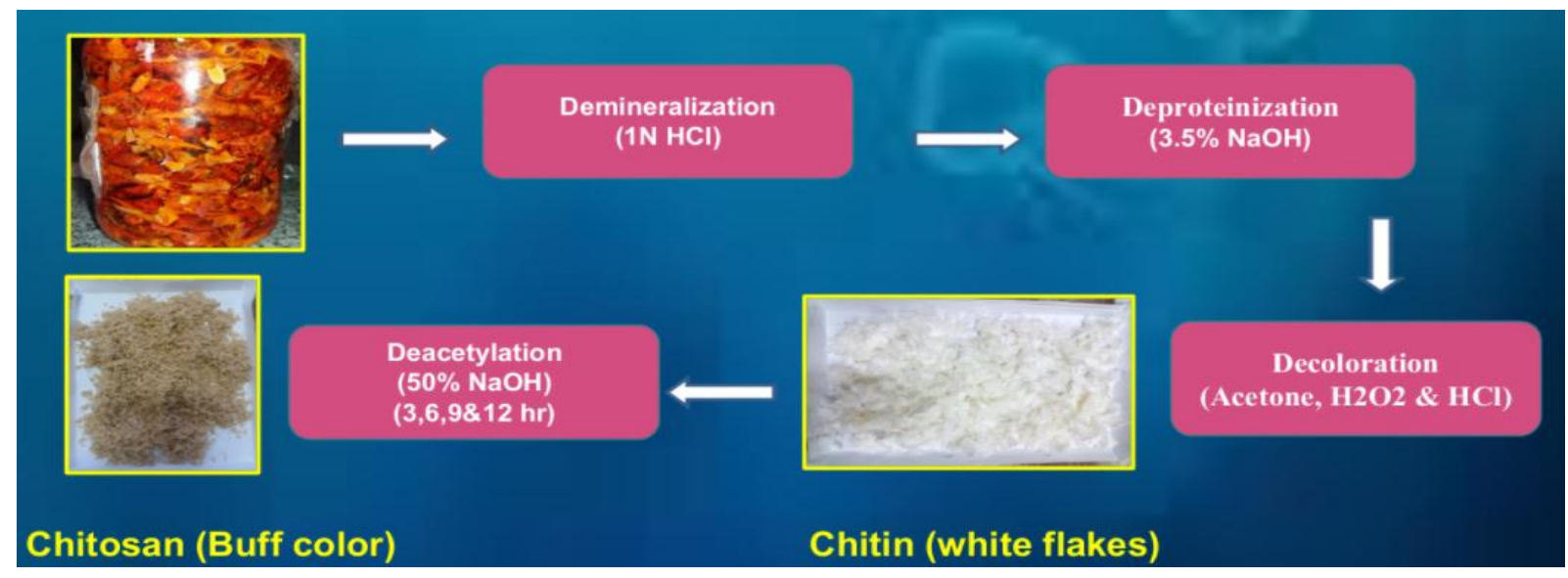

Fig. 4. Extraction of chitin from the exoskeleton wastes of Procambarus clarkii and its conversion into CS (El-Naggar, 2020)

\subsection{Deacetylation of chitin}

This process can be carried out chemically or enzymatically.

\subsubsection{Chemical deacetylation}

Chemical deacetylation is the most used method that depends on time and temperature of reaction. Chemical deacetylation can be heterogeneous or homogeneous. In the heterogenous deacetylation, chitin is added to $\mathrm{NaOH}$ at high temperature $\left(100^{\circ} \mathrm{C}\right)$ (Lamarque et al., 2005 and Younes \& Rinaudo, 2015). On the other hand, in the homogenous deacetylation, chitin is added to $\mathrm{NaOH}$ and $\mathrm{H}_{2} \mathrm{O}$ in a ratio of $1: 10: 1.5$, respectively at $25^{\circ} \mathrm{C}$ for about $3 \mathrm{hrs}$ followed by grinding the precipitate in a way that allows producing 48-55\% degree of deacetylation (Younes \& Rinaudo, 2015).

\subsubsection{Enzymatic deacetylation}

This method is usually used to avoid the disadvantages of the chemical operation, such as energy consumption and alkaline waste products that are considered as biohazards. The enzymatic deacetylation is favored because it is easily controlled, producing high quality 
CS (Younes \& Rinaudo, 2015). On the contrary, one of the major disadvantages of this method is that the low molecular weight chitin cannot be detected (Lamarque et al., 2005).

\subsubsection{Degree of deacetylation of CS}

Chang et al. (1997) reported that the best degree of deacetylation (DD) was produced after $6 \mathrm{hrs}$ of chitin treatment in an alkaline medium. They added that, upon increasing the temperature or $\mathrm{NaOH}$ concentration, an increase in the degree of deacetylation of the resultant CS was detected. The previous authors concluded that the maximum DD occurred at a temperature of $107^{\circ} \mathrm{C}$ and a treatment with $60 \% \mathrm{NaOH}$.

Contrarily, Aldila et al. (2020) found that, when $\mathrm{NaOH}$ concentration was consonant, a decline in the DD was detected upon increasing the temperature from $30^{\circ} \mathrm{C}$ to $60^{\circ} \mathrm{C}$ to $90^{\circ} \mathrm{C}$. They deduced that, as $\mathrm{NaOH}$ concentration changed from $20 \%$ to $40 \%$ and then to $60 \%$ while keeping the degree of temperature constant, the DD increased with increasing the concentration of $\mathrm{NaOH}$. Furthermore, the previous authors added that, the optimum conditions of temperature and $\mathrm{NaOH}$ concentration for the optimization of CS were $30^{\circ} \mathrm{C}$ and $60 \% \mathrm{NaOH}$, respectively.

\section{CSNP: characteristics and preparation}

Nanotechnology has become a paramount technology in the $21^{\text {st }}$ century. It is an emerging technology influencing the material division at a nanoscale of 1-100 $\mathrm{nm}$ that can change properties of materials and increase its potential to be utilized due to its increasing surface area that allows using nanoparticles in various applications (Rathore \& Mahesh, 2021).

CSNP are biodegradable, biocompatible and non-toxic materials which can be used in drug delivery, gene delivery and therapeutics, in agriculture as biopesticides, and they have been proved to act as effective feed additives for fish (Felt $\boldsymbol{e t}$ al., 1998 and Augustine $\boldsymbol{e t}$ al., 2019). Additionally, CSNP are favored for their small size that increases the available surface area to interact with biological support. Remarkably, CSNP boost the bioavailability of essential compounds, enable efficient uptake of the body cells and they deeply penetrate into the targeted sites (Alishahi et al., 2011).

In addition, CSNP can be implemented in different applications; namely, antioxidants, feed additive as growth promoter and immunostimulants, drug carriers, water treatment and hemocompatibility agents as well as phagocytic activity inducers (El-Naggar et al., 2021).

\subsection{Preparation of CSNP}

Different approaches have been used in the synthesis of CSNP, such as ionotropic gelation (Calvo et al., 1997), spray drying (Ngan et al., 2014) and water in emulsion crosslinking (Riegger et al., 2018). It is noteworthy mentioning that ionotropic gelation is regarded as the best technique due to its simplicity and lack of harsh organic solvent, homogenization or sonication (Calvo et al., 1997). The latter method involves physical crosslinking with sodium triphosphate (TPP). It was found that during the nanoparticles synthesis, the variation in the concentration of the polyanion sodium tripolyphosphate (TPP) and CS 
highly affects the physico-chemical characteristics of the resultant nanoparticles, and subsequently impact the performed application (Shard et al., 2014).

\subsection{Surface morphology of CS and CSNP}

Scanning electron microscopy analyses revealed that CS has three main surface morphologies; 1 . a surface with both nanofibers and nanopores, which is considered the most common morphology (Paulina $\boldsymbol{e t}$ al., 2006), 2. A hard and rough surface lacking nanofibers and nanopores, such as that isolated from Daphnia sp. (Kaya et al., 2013) and 3. A surface that is composed of nanofibers, such as that found in certain insect species and crustaceans (Kaya et al., 2014).

Notably, the surface morphology of CS differs in different species. Arasukumar et al. (2019) mentioned that CS extracted from Thenus unimaculatus is non-porous with flat lamellar surface. The previous authors added that the surface of the resultant CS appears in the form of clustered crystals with a rough surface (Fig. 5).

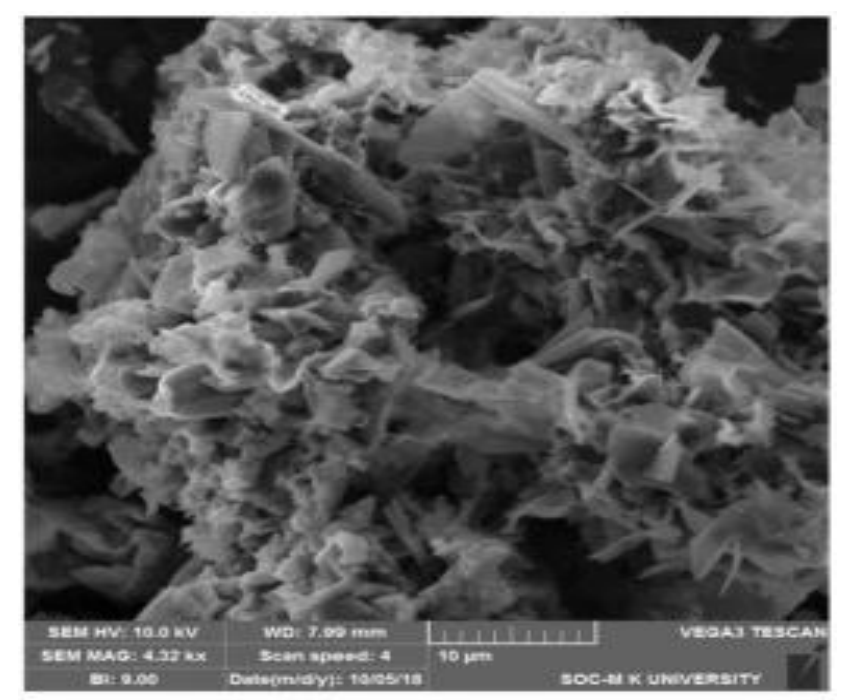

Fig. 5. Scanning electron micrograph of CS extracted from Thenus unimaculatus, showing rough, clustered and crystalline structure (Arasukumar et al., 2019)

On the contrary, scanning electron microscopy of CS extracted from Procambarus clarkii showed that the resultant CS lacks nanopores and nanofibers and appeared as flakes with rough and smooth surface. The higher magnification of the flakes indicated that they contain smooth fibers (El-Naggar et al., 2019) (Figs. 6A\&B). The previous authors added that transmission electron microscopy of the resultant CS appeared as anastomosing network of fibers (Fig. 7). 

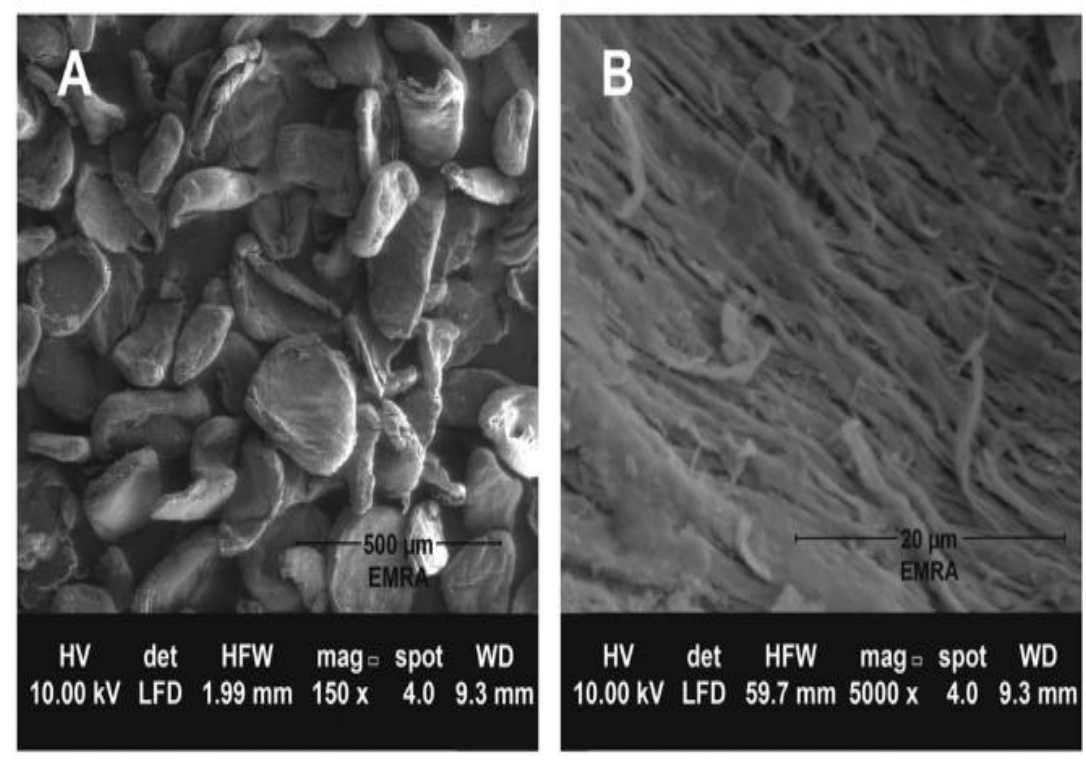

Fig. 6. Scanning electron micrographs of CS prepared from the exoskeleton of Procambarus clarkii showing: (A) Flakes with a rough and hard surface. (B) Higher magnification of a flake with numerous fibers (El-Naggar et al., 2019)

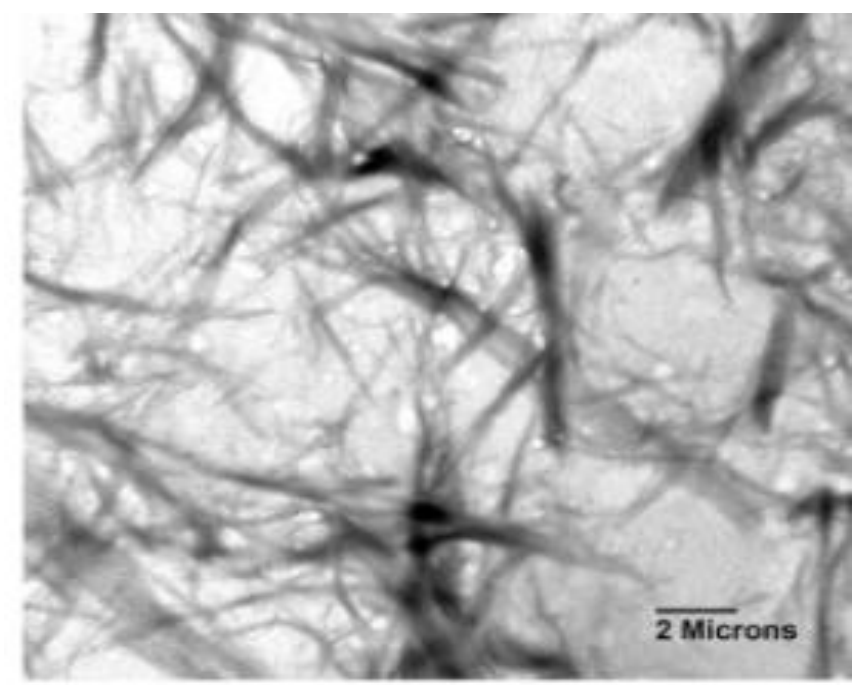

Fig. 7. Transmission electron micrograph of CS showing anastomosing network of fibers (El-Naggar et al., 2019).

\subsection{CSNP surface morphology}

El-Naggar et al. (2019) and Omidi \& Kakanejadifard (2019) reported that, CSNP are spherical in shape with smooth margins, forming the common morphology of the CSNP (Fig. 8). The former authors added that the optimum condition for the nanoparticles formation was obtained by applying CS to TPP in the ratio of 1:1. Moreover, they postulated that, in case of increasing the concentration of CS or TPP, the obtained nanoparticles become large and aggregated, respectively. 


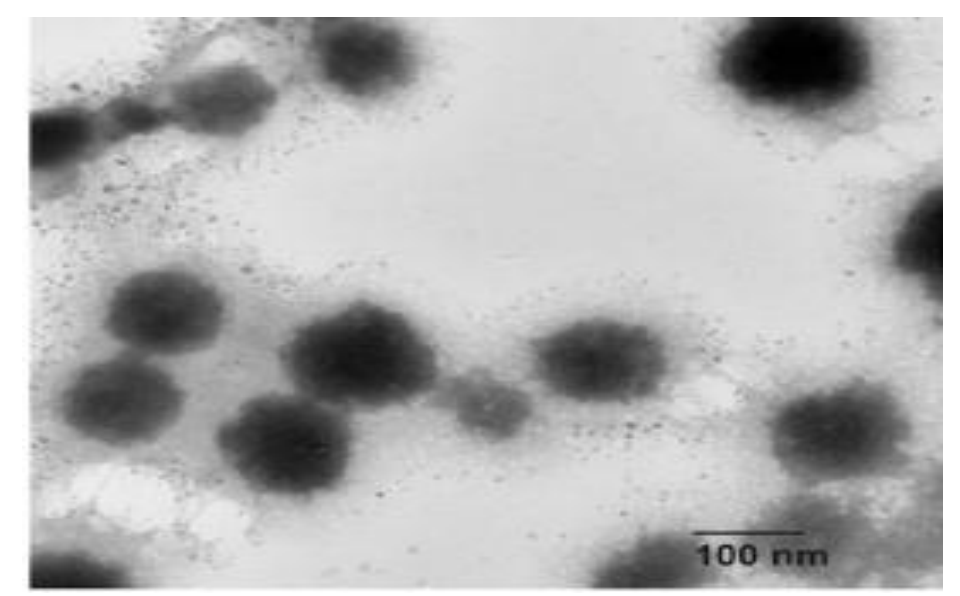

Fig. 8. Transmission electron micrograph of CSNP showing their spherical shape with smooth margins (El-Naggar et al., 2019).

\section{CS and CSNP nanoparticles applications in fish aquaculture}

CS and CSNP have widely been used in various applications due to their low side effects and their ability to enhance fish growth performance (GP), antioxidant activity and immune response (Gopalakannan \& Arul, 2006; Wang \& Li, 2011; Abd El-Naby et al., 2019 and El-Naggar, 2020). In addition, CS and CSNP can be used as drug carriers (Wu $\boldsymbol{e t}$ al., 2020 and Thanou et al., 2001). Moreover, CS and its derivatives are used in water treatment due to their chelating ability of heavy metals (Gamage \& Shahidi 2007; Fan $\boldsymbol{e t}$ al., 2017 and Zareie $\boldsymbol{e t}$ al., 2019). In this respect, CS and CSNP were proved to enhance water quality (Udo \& Anwana, 2018).

\subsection{CS and CSNP as feed additives}

Ogunkalu (2019) found that fish feed is a radical factor for the determination of the ability of fish to grow and reproduce. The afore-mentioned author added that the high cost of protein source (fish meal), which is the most expensive component of fish feed, causes a serious limitation in aquaculture. Moreover, the author suggested using optimum amounts of feed additives or feed supplementations to increase the growth rate of fish with minimal amounts of fish meal that would, in turn, reduce fish mortality. Feed additives are edible substances added to the animal feed in small quantities to enhance feed quality, which in return, enhance fish growth performance and reduce their mortality rate (Dada, 2015). ElNaggar (2020) reported that, due to the escalating price of fish meal, it is recommended to search for alternative protein sources, particularly plant protein source. The author added that the plant-based diets lack some essential nutritional components, which affect both the growth performance of fish as well as their survival rate. In this context, the author recommended the addition of CS and CSNP to plant-based diets to enhance the growth performance and immune response of Oreochromis niloticus. Several studies recommended the use of CS and CSNP as immunostimulants and growth promoting factors (Gopalakannan \& Arul, 2006; Wang \& Li 2011; Alishahi et al., 2014; Ranjan et al., 2014; Abd El-Naby et al., 2019; Abdel-Tawwab et al., 2019 and Abdel-Ghany \& Salem, 2020). 


\subsubsection{Effect of CS and CSNP on the growth performance of fish}

Abdel-Ghany and Salem (2020) reported that the optimal level of CS and CSNP to perform the best growth promoting effect depends mainly on animal species. It was found that the supplementation of diets with CS did not affect the growth performance of sea bream and Japanese eel (Kono et al., 1987). Moreover, in Paramigurunus dabryanus, the addition of CS combined with selenium (Se) with a dose of (0.6, 1,2 and 1.8) $\mathrm{mg}$ CS per $\mathrm{kg}$ diet for 60 days did not induce any change in fish growth performance (Victor et al., 2019).

It is worthy to mention that CS decreased the growth performance in case of using it as a supplemented additive to the feed of $O$. niloticus (Shiau \& Yu, 1999). Nevertheless, an increase in the growth performance of Paralichthys olivaceus, Cyprinus carpio and Dicentrachus labrax was detected due to CS supplementation (Gopalakannan \& Arul, 2006; Cha et al., 2008 and Zaki et al., 2015).

Zaki et al. (2015) explained CS effect in relation to its ability to induce healthy intestinal epithelium and its potential to promote microvilli growth, which leads to an increase in the absorbance surface of the microvilli. Reversely, the previous authors found that the increase in CS concentration in the diets caused a decline in the growth performance due to the intestinal blockage caused by an over growing of the microvilli.

It was found that, the growth performance of fish depended mainly on the administered dose of CS and CSNP. In the case of O. niloticus, the growth performance was enhanced by CS supplementation at a dose of $0.5 \mathrm{~g} / \mathrm{kg}$ diet (Wang \& Li, 2011). Furthermore, Chen et al. (2014) fortified diets for Carasius auratus juvenile with different doses of CS (1800, 4000, 7500, 10000 and 20000) mg of CS per kg diet for 75 days. They found that, $4000 \mathrm{mg}$ CS per $\mathrm{kg}$ diet formed the optimum level of CS supplementation. It induced the highest growth performance of fish by influencing the growth of the microvilli and the goblet cells in the intestinal epithelia (Figs. 9, 10 a\& b). Moreover, the use of CSNP supplementation at different levels in $O$. niloticus enhanced the growth performance by increasing both feed intake and feed utilization (Abd El-Naby et al., 2019; Abdel-Tawwab et al., 2019). Additionally, dietary fortification of CSNP for O. niloticus at a dose of $0.5 \mathrm{~g} / \mathrm{kg}$ induced a better health and increased fish disease resistance against pathogens (El-Naggar $\boldsymbol{e t}$ al., 2021). 

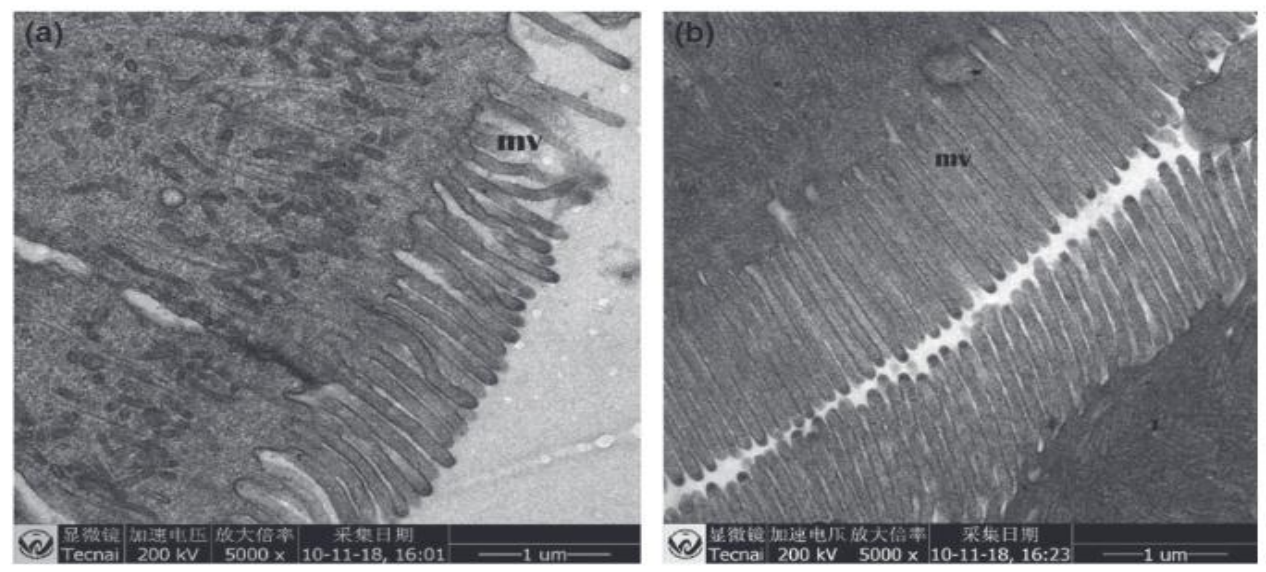

Fig. 9. Transmission electron micrograph of the intestinal microvilli of Carasius auratus juvenile monitoring: a) Control group with normal length of microvilli. b) $4000 \mathrm{mg} / \mathrm{kg} \mathrm{CS}$ supplemented group with proliferation of the microvilli (Chen et al., 2014)
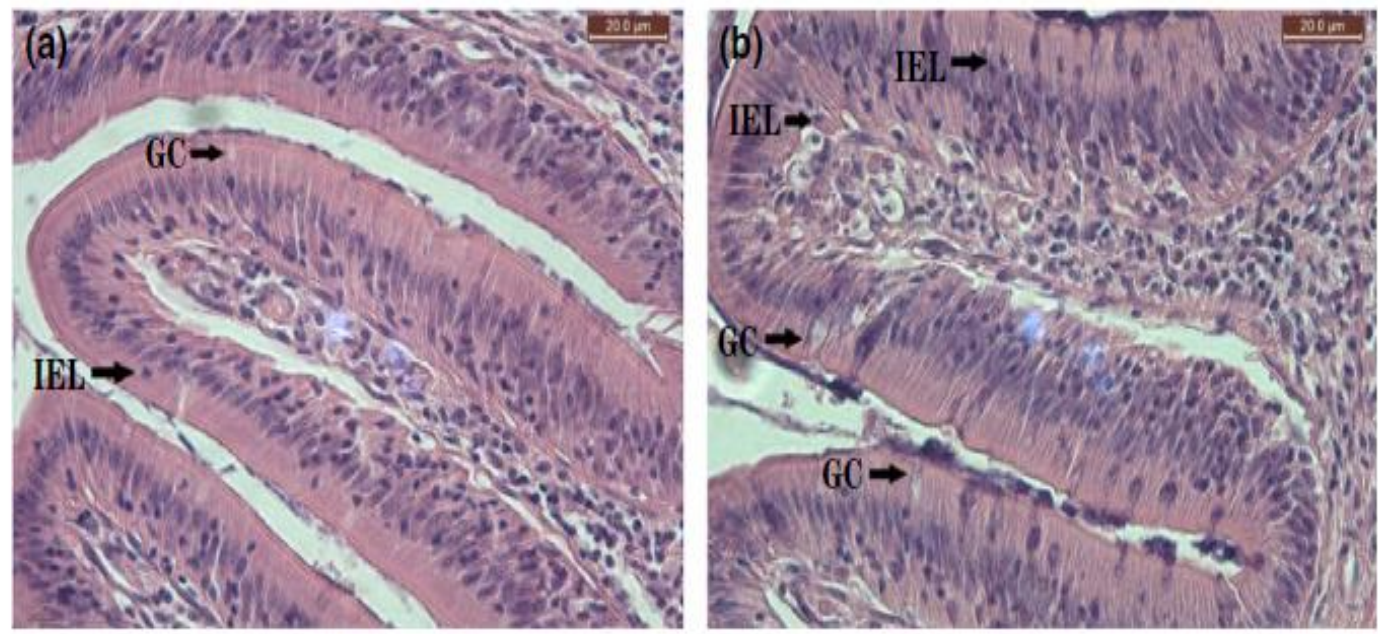

Fig. 10. Histological photomicrograph of intestinal microvilli of Carasius auratus juvenile; a) Control group showing normal structure of the intestinal microvilli and few goblet cells b) $4000 \mathrm{mg} / \mathrm{kg} \mathrm{CS}$ supplemented group showing increase in length of microvilli and number of goblet cells and intraepithelial lymphocytes (Chen et al., 2014)

\subsubsection{CS and CSNP as immunostimulants}

CS was determined to induce non-specific immunity, causing a reduction in the mortality rate (Meshkini et al., 2012; Zaki et al., 2015 and Abdel-Ghany \& Salem, 2020). In Oncorhyncus mykiss, CS supplementation at a concentration of $2.5 \mathrm{~g}$ per $\mathrm{kg}$ diet could significantly improve the survival rate of $O$. mykiss against stress conditions (Abdel-Ghany \& Salem 2020).

Ranjan et al. (2014) conducted an experiment on Lates calcarifer that were fed on diet supplemented with different doses of CS (0, 5, 10 and $20 \mathrm{~g} / \mathrm{kg}$ diet) for 60 days. Results showed that all groups fed CS supplemented diets had higher innate immune response 
compared to the control group. The previous authors added that the group fed $10 \mathrm{~g}$ of CS/ $\mathrm{kg}$ diet showed the highest hematological and innate immune parameters on day 45 of the experiment. Moreover, the previous dose recorded the significantly highest post- challenge survival on the $30^{\text {th }}$ day following Vibrio anguillarum challenge.

Furthermore, Mugil cephalus were fed diets fortified with CS at a graded manner dose (0, 5, 10 and $15 \mathrm{~g}$ per kg diet) (Meshkini et al., 2012). It was detected that 10 and $15 \mathrm{~g} \mathrm{CS}$ per kg diet supplemented groups recorded the highest innate immune response. Similarly, in Cyprinus carpio, it was found that the innate immune response was induced when CS was added to the diets (Gopalakannan \& Arul, 2006; Maqsood et al., 2010; Lin et al., 2011 and Alishahi et al., 2014).

Cha et al., (2008) explained the ability of CS as immunostimulant due to its ability to induce non-specific immunity. Moreover, Shibata et al. (1997) stated that CS can induce inflammatory cell function. Additionally, CS proved to increase serum lysosome activity in Epinephelus bruneus against vibrio virus infection (Harikrishnan et al., 2012).

In Paralichthys olivaeus, CS coated with moist pellet (MP) was found to increase the innate immune response upon its dietary fortification with different doses (1800, 4000, 7500, 10000 and $20000 \mathrm{~g} / \mathrm{kg}$ diet) (Cha et al., 2008). Moreover, in the previous study, the researchers found that CS caused a significant increase in the phagocytic and lysozyme activities. Furthermore, they postulated that $7500 \mathrm{~g} \mathrm{CS}$ per kg diet showed the highest ability to activate the innate immune response. Moreover, CS supplementation was found to be effective in the protection against bacterial infection in Labeo rohita inducing the fish immunity (Mastan, 2015). Najafabad et al. (2016) reported that CS supplementation improved the innate immune response and resistance against environmental changes in Caspian kutum fingerlings and ameliorated the immunological effect. Similar results were reported in the study of Yan et al. (2017) regarding Misgurnus angillicaudates.

For CSNP, Abd El-Naby et al. (2019) assessed that CSNP induced the innate immunity in $O$. niloticus by boosting the total WBCs and erythrogram elements. Moreover, it was found that CS-Se enhanced the immunity of Paramisgurnus dabryanus due to the increase in the lysosome activity and IgM level (Victor et al., 2019). Similar results were reported by Abdel-Tawwab et al. (2019) upon dietary fortification of $O$. niloticus with CSNP at different doses $(0.25,0.5,1$ and $2 \mathrm{~g} / \mathrm{kg}$ diet $)$. Briefly, CSNP have favorable effects on aquaculture and fish farming industry due to CSNP the immunostimulatory effects on fish (Cha et al., 2008 and Ahmed et al., 2019).

\subsection{CS and CSNP as antioxidants}

CS and many of its derivatives have antioxidant activity (Li et al., 1992). The antioxidant ability of CS is attributed to its chelating activity and free radical scavenging of the hydroxyl function group of CS, occuring by the donation of two electrons (Xie et al., 2001 and Abdel-Ghany \& Salem, 2020).

Kim \& Thomas (2007) reported that diets supplemented with CS showed high antioxidant activity and low lipid oxidation. Moreover, CS increased the efficiency of the 
antioxidant system in Cyprinus carpio when CS was supplied either alone or combined with vitamin C (Mehrpak et al., 2015). Furthermore, in Misgurnus anguillicaudatus juvenile, the antioxidant activity was induced upon CS supplementation at a dose with a graded manner (0.5, 1, 2 and 5) (Yan et al., 2017).

Mehrpak et al. (2015) notified that supplementation of CS had no significant effect on the antioxidant activity of Cyprinus carpio. Notwithstanding, when it was used in combination with vitamin $\mathrm{C}$, it treated the reduction of the antioxidant capacity of Cyprinus carpio.

For CSNP, Abdel-Tawwab et al. (2019) determined that CSNP supplementation in doses of $0.25,0.5,1$ and $2 \mathrm{~g} / \mathrm{kg}$ diet enhanced the antioxidant activity of $O$. niloticus. In addition, Salmo salar showed high antioxidant activity and reduction in lipid oxidation upon CSNP fortification. Similarly, Abdel-Tawwab et al. (2019) postulated that the increase in CSNP dietary supplementation cause antioxidant activity enhancement.

\subsection{CS and CSNP as drug carriers}

Thanou et al. (2001) reported that CS acts as drug carrier due to its ability to affect tight junction, forcing it to open gates, and hence allowing hydrophilic drug molecules to enter the cell. However, some CS disadvantages were mentioned, including low delivery capacity on cell membrane compared to other drug delivery agents and its inefficiency in nature's $\mathrm{pH}$ (CS is effective at $\mathrm{pH}$ 6.5, however above this value its efficiency decreases). Therefore, the CS effect is limited in many of the intestinal regions such as ileum and jejunum. The previous authors and Kulkatni et al. (2017) added that, the upper-mentioned problem can be overcome by using N-N-N-trimethyl CS chloride (TMC), which is one of CS derivatives that acts as a drug carrier, since TMC is effective in wide $\mathrm{pH}$ range.

Vaccination carried by CS increased mucoadhesive potential in Paralichthys olivaceus (Tian et al., 2008). CS-DNA oral vaccine showed good results after microscopic examination for vaccinated Paralichthyus olivaceus fish, and it was found that CS had the potential to be used in drug delivery applications.

Contrarily, Valero et al. (2016) deduced that CS-DNA vaccine did not induce serum circulating IgM, which is a specific neutralizing antibody in Dicentrarchus labrax against noda virus. Moreover, they added that the vaccine did not induce immune-gene expression in the hind gut. On other hand, CS-DNA vaccine induced expression of genes related to cellmediated cytotoxicity and interferon pathways against the virus.

Wu et al. (2020) reported that CS is a promising drug carrier for fish aquaculture due to the incredibly development of the safe usage of CS in gene therapy. This happens because CS derivatives increase CS solubility in nucleic acids, increasing the cell reception of the drug carried by CS, and hence increase the drug uptake of the cells. The researchers added that CS-DNA vaccine protects fishes from infection either by bacteria or viruses through the enhancement of the survival rate by $45 \%: 82 \%$. Moreover, they attributed the positive effect of CS-DNA vaccine to its ability to induce immune related genes. 
CSNP can be used as drug carriers for biological compounds, such as proteins (Xu \& Du, 2003), oligonucleotides and DNA plasmid (Csaba et al., 2009). CSNP are promising new drug carriers (Shu \& Zhu, 2000). CSNP are used as carriers for antioxidants causing an enhancement of the immune system (Ramos et al., 2005). Vimal et al. (2014), Zhao et al. (2014) and Ahmed et al. (2019) related CSNP drug carrying ability to the high potential of CSNP to deeply penetrate the tissues, allowing the drug to reach its specified location. Consequently, Vimal et al. (2014) considered CSNP are useful oral DNA vaccines with respect to fish. It was reported that $\mathrm{CS}$ and its derivatives can be eliminated through the kidney, and this makes CS and CSNP suitable for medical and pharmaceutical applications (Pan et al., 2002 and Ji et al. 2015).

Ferosekhan et al. (2014) reported that CSNP are used in oral delivery of drugs, vitamins and DNA vaccines because they deliver drugs to fish gastrointestinal tract. In addition, they increase the mucoadhesive potential of the intestine and thus, the intestinal absorption for drug increases.

Labeo rohita fish was immunized with CSNPs-DNA vaccine against Edwardisella tarda bacteria; this vaccine contained related immune-genes of these bacteria, allowing their expression (Kole et al., 2018). The previous study noted that the maximal expression of IgM in the liver, kidney and spleen of fish was attributed to immune gene carried vaccine.

\subsection{CS and CSNP in treatment of fish farms wastewaters}

Heavy metals are naturally occurring elements that have a high atomic weight and a density at least five times greater than that of water. They are toxic even at low exposure levels (Tchounwou et al., 2012). Many agents were used for water treatment, one of which is aluminum. Aluminum based residues showed good results as water treatment agents, although it was found that aluminum causes many neurologic diseases such as Alzheimer (Iber et al., 2021).

Gamage \& Shahidi (2007) noted that CS is an effective coagulating agent that is able to remove the heavy metals ions $(\mathrm{Hg}, \mathrm{Zn}, \mathrm{Fe}, \mathrm{Pb}$ and $\mathrm{Cu}$ ) from fish farms wastewater. Moreover, the previous authors and Yu et al. (2013) as well as Abd-Elhakeem et al. (2016) mentioned that heavy metal removal was achieved by chelation.

Yu et al. (2013) assessed that CS contains many functional groups that react with the metal ions; this reaction depends on the composition and the $\mathrm{pH}$ of water. The chelation mechanism occurs due to the ability of CS nitrogen atoms of the amine groups to make covalent bonds with $\mathrm{Cu}$ (metal ions), hence allowing ions removal. Moreover, it was found that the chemical modifications of CS improved CS ability to remove metal ions from water (Sobahi et al., 2014). This study revealed that aldehyde and carbon modifications are good for metal removal leading to water treatment. Additionally, it was found that $\left(\mathrm{Fe}_{3} \mathrm{O}_{4} / \mathrm{CS}\right)$ shows a great ability in $\mathrm{Pb}$ and $\mathrm{Cd}$ absorption. The previous researchers related the ability of high absorbance to the high functional group of CS (amino group and hydroxyl group) (Fan et al., 2017). 
On the other hand, CSNP show a great ability to remove $\mathrm{Cu}$ (metal ions) from water (Yu et al., 2013). In the previous study, the authors mentioned that ability of CSNP to absorb copper ions is directly proportional with the concentration of the solution (water). Similar results supported the high efficiency of CSNP to absorb heavy metals (Abd-Elhakeem et al., 2016). The researchers in the previous study found that both CS and CSNP can remove heavy metal ions from water. They added that CS is a good agent that can be used in simple filtration water systems. However, they recommended the use of CSNP due to their higher efficiency of heavy metal chelation.

Seyedmohammadi et al. (2016) compared between the ability of CS and CSNP with regard to absorption; they found that CSNPs is more effective than CS in $\mathrm{Zn}$ removal. The previous authors reported the optimal conditions at which CS and CSNPs showed their most absorbance ability (90.80\% and $99.10 \%$, respectively). Conditions preferred include $\mathrm{pH} 7$, temperature $25^{\circ} \mathrm{C}$ and $10 \mathrm{mg}$ of $\mathrm{Zn}$. They added that CSNP ability to remove heavy ions from water is higher than CS due to their small size particles that increase the surface area of absorption and number of exposed functional group. Furthermore, it was reported that CSNP have the capacity for $(\mathrm{Pb}$ : lead) removal from water which is higher compared to that of $\mathrm{CS}$ (Zareie et al., 2019).

\section{CONCLUSION}

The current review was conducted to address the importance of CS and CSNP in fish aquaculture. It was found that CS and CSNP are good feed additives that promote the growth performance and stimulate the immune system, especially the innate immune response. In addition, they are used as drug carriers, antioxidants and water treatment agents. Moreover, in fish aquaculture, CSNP proved to be favored by the recent authors than CS due to their larger surface area, bioavailability and deep penetration to the target sites. Therefore, CSPN is recommended to be used worldwide, and particularly in Egypt to enhance fish aquaculture quality.

\section{REFERENCES}

Abd El-Naby, F.S.; Naiel, M.A.E.; Al-Sagheer, A.A. and Negm, S.S. (2019). Dietary chitosan nanoparticles enhance the growth, production performance, and immunity in Oreochromis niloticus. Aquacult., 501: 82-89.

Abdel-Ghany, H.M. and Salem, M.E.S. (2020). Effects of dietary chitosan supplementation on farmed fish; a review. Rev. Aquacult., 12(1): 438-452.

Abd-Elhakeem, M.A.; Ramadan, M.M. and Basaad, F.S. (2016). Removing of heavymetals from wate4r by chitosan nanoparticles. J. Adv.Chem., 11(7): 37653771. 
Abdel-Tawwab, M.; Razek, N.A. and Abdel-Rahman, A.M. (2019). Immunostimulatory effect of dietary chitosan nanoparticles on the performance of Nile tilapia, Oreochromis niloticus (L.). Fish Shellfish Immunol., 88: 254-258.

Ahmed, I.; Reshi, Q.M. and Fazio, F. (2020). The influence of the endogenous and exogenous factors on hematological parameters in different fish species: a review. Aquacult. Int., 28: 869-899.

Ahmed, F.; Soliman, F.M.; Adly, M.A.; Soliman, H.A.M.; El-Matbouli, M. and Saleh, M. (2019). Recent progress in biomedical applications of chitosan and its nanocomposites in aquaculture: A review. Res. Vet. Sci, 126: 68-82.

Aldila, H.A.; Fabiani.V.A.; Dalimunthe, D.Y. and Lrwanto, R. (2020). The effect of deproteinization temperature and $\mathrm{NaOH}$ concentration on deacetylation step in optimizing extraction of chitosan from shrimp shells waste. IOP Conference Series: Earth and Environmental Science.

Alishahi, A.; Mirvaghefi, A.; Tehrani, M.R.; Farahmand, H. Koshio, S.; Dorkoosh, F.A. and Elsabee, M.Z. (2011). Chitosan nanoparticle to carry vitamin C through the gastrointestinal tract and induce the non-specific immunity system of rainbow trout (Oncorhynchus mykiss). Carb. Polym., 86(1):142-146.

Alishahi, M.; Rad, E.; Zarei, M. and Ghorbanpour, M. (2014). Effect of dietary chitosan on immune response and disease resistance in Cyprinus carpio. Iran. J. Vet. Med., 8: 125-133.

Arasukumar, B.; Prabakaran, G.; Gunalan, B. and Moovendhan, M. (2019). Chemical composition, structural features, surface morphology and bioactivities of chitosan derivatives from lobster Thenus unimaculatus shells. Int. J. Biol. Macromol., 135: 1237-1245.

Augustine, R.; Dan, P.; Schlachet, I.; Rouxel, D.; Menu, P. and Sosnik, A. (2019). Chitosan ascorbate hydrogel improves water uptake capacity and cell adhesion of electro spun poly(epsilon-caprolactone) membranes, Int. J. Pharmaceut., 559: 420426.

Calvo, P.; Remunan-Lopez, C.; Vila-Jato, J.L. and Alonso, M.J. (1997). Novel ydrophilic chitosan-polyethylene oxide nanoparticles as protein carrier. J. Appl. Polym. Sci., 63: $125-132$.

Cha, S.H.; Lee, J.S.; Song, C.B.; Lee, K.J. and Jeon, Y.J. (2008). Effects of chitosancoated diet on improving water quality and innate immunity in the olive flounder, Paralichthys olivaceus. Aquacult., 278(1-4): 110-118.

Chang, K.L.; Tsai, G.; Lee, J. and Fu, W.R. (1997). Heterogeneous N-deacetylation of chitin in alkaline solution. Carb. Res., 307: 327-332.

Chawla, S.P.; Kanatt, S.R. and Sharma, A.K. (2015). Chitosan. In "Polysaccharides: Bioactivity and Biotechnology". Springer Int. Pub. Pp: 219-246. https://doi.org/10.1007/978-3-319-16298-0_13. 
Chen, Y.; Zhu, X.; Yang, Y.; Han, D.; Jin, J. and Xie, S. (2014). Effect of dietary chitosan on growth performance, haematology, immune response, intestine morphology, intestine microbiota and disease resistance in gibel carp (Carassius auratus gibelio). Aquacult. Nutr., 20(5): 532-546.

Csaba, N.; Köping-Höggård, M. and Alonso, M.J. (2009). Ionically crosslinked chitosan/tripolyphosphate nanoparticles for oligonucleotide and plasmid DNA delivery. Int. J. Pharmaceut., 382(1-2): 205-214.

Dada, A.A. (2015), Improvement of tilapia (Oreochromis niloticua Linnaeus, 1758) growth performance fed three commercial feed additives in diets. J. Aquacult. Res. Dev., 6: 325-327.

El-Naggar, M. (2020). Effects of chitosan nanoparticles on the growth rate and reproductive performance of the Nile Tilapia, Oreochromis niloticus. Doctoral Dissertation. Faculty of Science, Ain Shams University, Cairo, Egypt.

El-Naggar, M.M.; Abou-Elmagd, W.S.I.; Suloma, A.; El-Shabaka, H.A.; Khalil, M.T. and Abd El-Rahman, F.A. (2019). Optimization and physico-chemical characterization of chitosan and chitosan nanoparticles extracted from the crayfish Procambarus clarkii Wastes. J.Shellfish Res., 38(2): 385-395.

El-Naggar, M.; Salaah, S.; El-Shabaka, H.; El-Rahman, F.A.; Khalil, M. and Suloma, A. (2021). Efficacy of dietary chitosan and chitosan nanoparticles supplementation on health status of Nile tilapia, Oreochromis niloticus (L.). Aquacult. Rep., 19: 100828.

Fan, H.L.; Zhou, S.F.; Jiao, W.Z.; Qi, G.S. and Liu, Y.Z. (2017). Removal of heavy metal ions by magnetic chitosan nanoparticles prepared continuously via high-gravity reactive precipitation method. Carb. Polym., 174: 1192-1200.

Felt, O.; Buri, P. and Gurny, R. (1998). Chitosan: a unique polysaccharide for drug delivery. Drug Dev. Ind. Pharm., 24(11): 979-993.

Ferosekhan, S.; Gupta, S.; Singh, A.; Rather, M.; Kumari, R.; Kothari, D.; Pal, A. and Jadhao, S. (2014). RNA-loaded chitosan nanoparticles for enhanced growth, immunostimulation and disease resistance in fish. Curr. Nanosci., 10(3): 453-464.

Gamage, A. and Shahidi, F. (2007). Use of chitosan for the removal of metal ion contaminants and proteins from water. Food Chem., 104(3): 989-996.

General Authority for Fisheries Resources Development (GAFRD) (2020). Yearly Book for fish Production in Egypt, Agriculture Ministry.

Gopalakannan, A. and Arul, V. (2006). Immunomodulatory effects of dietary intake of chitin, chitosan and levamisole on the immune system of Cyprinus carpio and control of Aeromonas hydrophila infection in ponds. Aquacult., 255(1-4): 179-187.

Harikrishnan, R.; Kim, J.S.; Balasundaram, C. and Heo, M.S. (2012). Immunomodulatory effects of chitin and chitosan enriched diets in Epinephelus bruneus against Vibrio alginolyticus infection. Aquacult., 326-329: 46-52. 
Iber, B.T.; Okomoda, V.T.; Rozaimah, S.A. and Kasan, N.A. (2021). Eco-friendly approaches to aquaculture wastewater treatment: Assessment of natural coagulants vis-a-vis chitosan. Bioresour. Technol. Rep., 15: 100702.

Ji, J.; Torrealba, D.; Ruyra, À. and Roher, N. (2015). Nanodelivery systems as new tools for immunostimulant or vaccine administration: Targeting the fish immune system. Biol., 4(4): 664-696.

Kaleem, O. and Sabi, AF.B.S. (2021). Overview of aquaculture systems in Egypt and Nigeria, prospects, potentials and constrains. Aquacult. Fish., 6: 535-547.

Kaya, M.; Baran, T.; Mentes, A.; Asaroglu, M.; Sezen, G. and Tozak, K.O. (2014). Extraction and characterization of a-chitin and chitosan from six different aquatic invertebrates. Food Biophys., 9: 145-157.

Kaya, M.; Sargin, I.; Tozak, K.O.; Baran, T.; Erdogan, S. and Sezen, G. (2013). Chitin extraction and characterization from Daphnia magnaresting eggs. Int. J. Biol. Macromol., 61:459-464.

Khosravi-Katuli, K.; Prato, E.; Lofrano, G.; Guida, M.; Vale, G. and Libralato, G. (2017). Effects of nanoparticles in species of aquaculture interest. Environ. Sci. Pollut. Res., 24: 17326-17346.

Kim, K.W. and Thomas, R.L. (2007). Antioxidative activity of chitosans with varying molecular weights. Food Chem., 101(1): 308-313.

Kole, S.; Kumari, R.; Anand, D.; Kumar, S.; Sharma, R.; Tripathi, G.; Makesh, M.; Rajendran, K.V. and Bedekar, M.K. (2018). Nanoconjugation of bicistronic DNA vaccine against Edwardsiella tarda using chitosan nanoparticles: Evaluation of its protective efficacy and immune modulatory effects in Labeo rohita vaccinated by different delivery routes. Vaccine, 36(16): 2155-2165.

Kono, M.; Matsui, T. and Shimizu, C. (1987). Effect of chitin, chitosan, and cellulose as diet supplements on the growth of cultured fish. Nippon Suisan Gakk., 53: 125-129.

Kulkarni, A.D.; Patel, H.M.; Surana, S.J.; Vanjari, Y.H.; Belgamwar, V.S. and Pardeshi, C.V. (2017). N, N,N-Trimethyl chitosan: An advanced polymer with myriad of opportunities in nanomedicine. Carb. Polym., 157: 875-902.

Kurita, K. (2006). Chitin and chitosan: functional biopolymers from marine crustaceans. Mar. Biotechnol., 8(3): 203-226.

Lamarque, G.; Christophe, V. and Domard, A. (2005). New Route of deacetylation of $\alpha$ and $\beta$-Chitins by means of freeze-pump out-thaw cycles. 6(3): 1380-1388.

Li, Q.; Dunn, E.T.; Grandmaison, E.W. and Goosen, M.F.A. (1992). Applications and properties of chitosan. J. Bioact. Compat. Polym., 7(4): 370-397.

Lin, S.; Pan, Y.; Luo, L. and Luo, L. (2011). Effects of dietary $\beta$-1,3-glucan, chitosan or raffinose on the growth, innate immunity and resistance of koi (Cyprinus carpio koi). Fish Shellfish Immunol., 31(6): 788-794. 
López-García, J.; Lehocký, M.; Humpolíček, P. and Sáha, P. (2014). HaCaT keratinocytes response on antimicrobial atelocollagen substrates: Extent of cytotoxicity, cell viability and proliferation. J. Funct. Biomat., 5(2): 43-57.

Maclean, N. (2003). 5. Genetically modified fish and their effects on food quality and human health and nutrition. Trends Food Sci.Technol.,14(5-8): 242-252.

Maqsood, S.; Singh, P.; Samoon, H. and Khansaheb, A.B. (2010). Effect of dietary chitosan on non-specific immune response and growth of Cyprinus carpio challenged with Aeromonas hydrophila. Int. Aquat. Res., 2: 77-85.

Mastan, S.A. (2015). Use of Immunostimulants in aquaculture disease management. 2(4): 277-280.

Mehrpak, M.; Banaee, M.; Haghi, B.N. and Noori, A. (2015). Protective effects of vitamin $\mathrm{C}$ and chitosan against cadmium-induced oxidative stress in the liver of Common Carp (Cyprinus carpio). Iran. J. Toxicol., 9: 1360-1367.

Meshkini, S.; Tafy, A.-A.; Tukmechi, A. and Farhang-Pajuh, F. (2012). Effects of chitosan on hematological parameters and stress resistance in rainbow trout (Oncorhynchus mykiss). Vet. Res. Forum., 3(1):49-54.

Najafabad, M.K.; Imanpoor, M.R.; Taghizadeh, V. and Alishahi, A. (2016). Effect of dietary chitosan on growth performance, hematological parameters, intestinal histology and stress resistance of Caspian kutum (Rutilus frisii kutum Kamenskii, 1901) fingerlings. Fish Physiol. Biochem., 42(4): 1063-1071.

Ngan, L.T.K.; Wang, S.-L.; Hiep, D.M.; Luong, P.M.; Vui, N.T.; Dinh, T.M. and Dzung, N.A. (2014). Preparation of chitosan nanoparticles by spray drying, and their antibacterial activity. Res. Chem. Intermed., 40: 2165-2175.

No, H.K. and Meyers, S.P. (2010). Preparation and characterization of chitin and chitosanA Review. J. Aquat. Food Prod. Technol., 4(2): 27-52.

Ogunkalu, O.A. (2019). Effects of feed additives in fish feed for improvement of aquaculture uses of natural additives in seafood. Euras. J. Food Sci. Technol., 3(2): 49-57.

Omidi, S. and Kakanejadifard, A. (2019). Modification of chitosan and chitosan nanoparticle by long chain pyridinium compounds: Synthesis, characterization, antibacterial, and antioxidant activities. Carb. Polym., 208: 477-485

Pakizeh, M.; Moradi, A. and Ghassemi, T. (2021). Chemical extraction and modification of chitin and chitosan from shrimp shells. Europ. Polym. J., 159(5): 110709.

Pan, Y.; Li, Y.-J.; Zhao, H.-Y.; Zheng, J.-M.; Xu, H.; Wei, G.; Hao, J.-S. and Cui, F.-D. (2002). Bioadhesive polysaccharide in protein delivery system: chitosan nanoparticles improve the intestinal absorption of insulin in vivo. In. J. Pharm., 249: 139-147.

Paulino, A.T.; Simionato, J.I.; Garcia, A.J. and Nozaki, J. (2006). Characterization of chitosan and chitin produced from silkworm chrysalis. Carb. Polym., 64: 98-103. 
Perini, M.; Nardin, T.; Venturelli, M.; Pianezze, S. and Larcher, R.(2020). Stable isotope ratio analysis as a fast and simple method for identifying the origin of chitosan". Food Hydrocoll., 101: 105516. https://doi.org/10.1016/j.foodhyd.2019.105516

Ramos, E.A.; Relucio, L.V.; Aurora, C. and Torres-Villanueva, T. (2005). Gene expression in Tilapia following oral delivery of chitosan-encapsulated plasmid DNA incorporated into fish feeds. Mar. Biotechnol., 7: 89-94.

Ranjan, R.; Prasad, K.P.; Vani, T. and Kumar, R. (2014). Effect of dietary chitosan on haematology, innate immunity and disease resistance of Asian seabass Lates calcarifer (Bloch). Aquacult. Res., 45(6): 983-993.

Rathore, A. and Mahesh, G. (2021). Public perception of nanotechnology: A contrast between developed and developing countries. Technol. Soc., 67: 10751.

Riegger, B.R.; Baurer, B.; Mirzayeva, A.; Tovar, G.E.M. and Bach, M. (2018). Systematic approach for preparation of chitosan nano-particles via emulsion crosslinking as potential adsorbent in waste-water treatment. Carb. Polym., 180:4654.

Saifuddin, N.M. and Palanisamy, K. (2005). Removal of heavy metal from industrial wastewater using chitosan coated oil palm shell charcoal. Electron. J. Biotechnol., 8(1): 43-53.

Seyedmohammadi, J.; Motavassel, M.; Maddahi, M.H. and Nikmanesh, S. (2016). Application of nanochitosan and chitosan particles for adsorption of $\mathrm{Zn}$ (II) ions pollutant from aqueous solution to protect environment. Model. Earth Syst. Environ., 2(3): 165 .

Shard, P.; Bhatia, A. and Sharma, D. (2014). Optimization and physico-chemical parameters on synthesis of chitosan nanoparticles by ionicgelation technique. Int. J. Drug Deliv., 6: 58-63.

Shiau, S.-Y. and Yu, Y.-P. (1999). Dietary supplementation of chitin and chitosan depresses growth in tilapia, Oreochromis niloticus X O. aureus. Aquacult., 179(1/4): 439-446.

Shibata, Y.; Foster, L.A.; Metzger, W.J. and Myrvik, Q.N. (1997). Alveolar macrophage priming by intravenous administration of chitin particles, polymers of $\mathrm{N}$-acetyl-Dglucosamine, in mice. Infect. Immunol., 65(5): 11734-11741.

Shu, X.Z. and Zhu, K.J. (2000). A novel approach to prepare tripolyphosphate/chitosan complex beads for controlled release drug delivery, Int. J. Pharm., 201(1): 51-58.

Sobahi, T.R.A.; Abdelaal, M.Y. and Makki, M.S.I. (2014). Chemical modification of chitosan for metal ion removal. Arab. J. Chem., 7(5): 741-746.

Tchounwou, P.B.; Yedjou, C.G.; Patlolla, A.K.; Sutton, D.J.; Tchounwou, P.B.; Yedjou, C.G.; Patlolla, A.K. and Sutton, D.J. (2012). Heavy metal toxicity and the environment. Exp. Suppl., 101: 133-164. 
Thanou, M.; Verhoef, J.C. and Junginger, H.E. (2001). Chitosan and its derivatives as intestinal absorption enhancers. Adv Drug Deliv. Rev., 1: S91-101.

Tian, J.; Yu, J. and Sun, X. (2008). Chitosan microspheres as candidate plasmid vaccine carrier for oral immunisation of Japanese flounder (Paralichthys olivaceus). Vet. Immunol. Immunopathol., 126(3-4): 220-229.

Udo, I. and Anwana, U. (2018). Effects of chitosan and chitosan nanoparticles on water Quality, growth performance, survival Rate and meat quality of the African Catfish, Clarias gariepinus, Nanosci., 17: 12-25.

Valero, Y.; Awad, E.; Buonocore, F.; Arizcun, M.; Esteban, M.Á.; Meseguer, J.; Chaves-Pozo, E. and Cuesta, A. (2016). An oral chitosan DNA vaccine against nodavirus improves transcription of cell-mediated cytotoxicity and interferon genes in the European sea bass juveniles gut and survival upon infection. Development. Comparat. Immunol., 65: 64-72.

Victor, H.; Zhao, B.; Mu, Y.; Dai, X.; Wen, Z.; Gao, Y. and Chu, Z. (2019). Effects of Sechitosan on the growth performance and intestinal health of the loach Paramisgurnus dabryanus (Sauvage). Aquacult., 498: 263-270.

Vimal, S.; Abdul Majeed, S.; Nambi, K.S.N.; Madan, N.; Farook, M.A.; Venkatesan, C.; Taju, G.; Venu, S.; Subburaj, R.; Thirunavukkarasu, A.R. and Hameed, A.S.S. (2014). Delivery of DNA vaccine using chitosan-tripolyphosphate (CS/TPP) nanoparticles in Asian sea bass, Lates calcarifer (Bloch, 1790) for protection against nodavirus infection. Aquacult., 420-421: 240-246.

Wang, Y. and Li, J. (2011). Effects of chitosan nanoparticles on survival, growth and meat quality of tilapia, Oreochromis nilotica. Nanotoxicol., 5(3): 425-431.

Wu, Y.; Rashidpour, A.; Almajano, M.P. and Metón, I. (2020). Chitosan-based drug delivery system: Applications in fish biotechnology, Polymers, 12(5): 1177.

Xie, W.; Xu, P. and Liu, Q. (2001). Antioxidant activity of water-soluble chitosan derivatives. Bioorg. Medic. Chem. Lett., 11(13): 1699-1701.

Xu, Y. and Du, Y. (2003). Effect of molecular structure of chitosan on protein delivery properties of chitosan nanoparticles. Int. J. Pharm., 250(1): 215-226.

Xu, Y.; Gallert, C. and Winter, J. (2008). Chitin purification from shrimp wastes by microbial deproteination and decalcification. Appl. Microbiol. Biotechnol., 79(4): 687-687.

Yan, J.; Guo, C.; Dawood, M.A.O. and Gao, J. (2017). Effects of dietary chitosan on growth, lipid metabolism, immune response and antioxidant-related gene expression in Misgurnus anguillicaudatus. Benef. Microbes, 8(3): 439-449.

Younes, I. and Rinaudo, M. (2015). Chitin and chitosan preparation from marine sources. Structure, properties and applications. Mar. Drugs, 13(3): 1133-1174. 
Yu, K.; Ho, J.; McCandlish, E.; Buckley, B.; Patel, R.; Li, Z. and Shapley, N.C. (2013). Copper ion adsorption by chitosan nanoparticles and alginate microparticles for water purification applications. Colloids Surf. A: Physicochem. Engin. Asp., 425: $31-41$.

Zaki, M.A.; Salem, M.E.-S.; Gaber, M.M. and Nour, A.M. (2015). Effect of chitosan supplemented diet on survival, growth, feed utilization, body composition and histology of Sea bass (Dicentrarchus labrax). World J. Eng. Technol., 3(4): 38-47.

Zareie, C.; Eshkalak, S.K.; Darzi, G.N.; Baei, M.S.; Younesi, H. and Ramakrishna, S. (2019). Uptake of $\mathrm{Pb}(\mathrm{II})$ Ions from simulated aqueous solution via nanochitosan. Coatings, 9(12): 862.

Zhao, L.; Su, C.; Zhu, B. and Jia, Y. (2014). Development and optimization of insulinchitosan nanoparticles. Trop.J. Pharm. Res., 13(1): 3-8. 